\title{
Laboreal
}

Volume 15 N$^{\circ} 2$ | 2019

Varia

\section{Portugal, 27 de abril de 1962 : a visibilidade da tragédia da silicose}

Portugal, 27 de abril de 1962: la visibilidad de la tragedia de la silicosis

Portugal, 27 avril 1962 : la visibilité de la tragédie de la silicose

Portugal, April 27, 1962: the visibility of the tragedy of silicosis

\section{Augusto Rogério Leitão}

\section{(2) OpenEdition}

Journals

\section{Edição electrónica}

URL: http://journals.openedition.org/laboreal/15318

DOI: $10.4000 /$ laboreal. 15318

ISSN: 1646-5237

\section{Editora}

Universidade do Porto

Refêrencia eletrónica

Augusto Rogério Leitão, "Portugal, 27 de abril de 1962 : a visibilidade da tragédia da silicose », Laboreal [Online], Volume $15 \mathrm{~N}^{\circ} 2$ | 2019, posto online no dia 01 dezembro 2019, consultado o 15 setembro 2020. URL : http://journals.openedition.org/laboreal/15318

Este documento foi criado de forma automática no dia 15 setembro 2020.

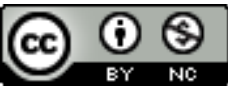

Laboreal está licenciado com uma Licença Creative Commons - Atribuição-NãoComercial 4.0 Internacional. 


\title{
Portugal, 27 de abril de 1962 : a visibilidade da tragédia da silicose
}

\author{
Portugal, 27 de abril de 1962: la visibilidad de la tragedia de la silicosis \\ Portugal, 27 avril 1962 : la visibilité de la tragédie de la silicose \\ Portugal, April 27, 1962: the visibility of the tragedy of silicosis
}

Augusto Rogério Leitão

\section{Introdução}

1 Em 27 de abril de 1962, foi adotado, pelo governo de Salazar, o Decreto-lei n.. 44307 relativo à silicose como doença profissional, que na época revestia dimensões socialmente dramáticas. Esta legislação estabelecerá um regime especial para a reparação dos danos sofridos pelos trabalhadores afetados por essa doença, que eram então sobretudo mineiros. Cria, para isso, a Caixa Nacional de Seguros de Doenças Profissionais (CNSDP), como instituição da Previdência social, que terá por missões principais gerir o seguro obrigatório e administrar os procedimentos que permitirão indemnizar os trabalhadores e os seus familiares

2 Este decreto altera a Lei n.o 1942 de 27 de junho de 1936, que ainda estava em vigor em 1962 e que tinha sido adotada no contexto histórico da primeira fase do Estado Novo corporativo de Salazar (Constituição de 1933) e da instituição da respetiva Previdência social : o Estatuto do Trabalho Nacional (Decreto-lei n.․ 23048, de 23 de setembro de 1933) e a Lei das Instituições de Previdência Social (Lei n.․ 1884, de 16 de março, de 1935), dentre as quais teremos de referir as Caixas Sindicais de Previdência de natureza corporativa, criadas por iniciativa dos Grémios e dos Sindicatos Nacionais (Decreto n. ${ }^{\circ}$ 25935 de 12 de Outubro de 1935) (Amaro, 2008).

3 Tal sobressalto político em relação à situação sanitária da silicose, expressou-se, desde logo, através da criação institucional dum seguro obrigatório gerido pelo Estado e inserido nas missões da previdência social. Tal progresso, em relação à reparação e à proteção social dessa doença profissional, terá lugar na conjuntura histórica do Estado 
salazarista dos finais dos anos 50, princípios dos anos 60 do século passado, caracterizada por uma dinâmica de industrialização e de modernização do país. Dinâmica essa apoiada por certas elites do regime que defendiam uma abertura à Europa (EFTA e CEE) e pelos grupos económicos que vinham se afirmando à sombra do regime ditatorial, tais como CUF, Champalimaud, Espírito Santo, Borges. Todavia, a partir de 1961-62 esses atores tiveram de integrar nessa dinâmica os problemas suscitados pelo início e pela continuação da guerra colonial em África (1961-1974).

\section{Os primeiros passos da doutrina do "risco profissional"}

4 Em Portugal, tal como nos outros países europeus, a legislação relativa à reparação dos danos causados pelas doenças profissionais foi adotada após a dos acidentes de trabalho, que surgiu pouco tempo depois da implantação da República (5 de outubro de 1910), através da Lei n. .83 , de 24 de julho, de 1913, atribuindo a responsabilidade (civil) objetiva ao empregador pelos acidentes de trabalho de que fossem vítimas os trabalhadores ao seu serviço. Consagra assim a denominada doutrina do "risco profissional", sem impor a obrigatoriedade de transferência da responsabilidade patronal para uma seguradora ou entidade equivalente, pública ou privada. Adota, com efeito, o modelo da lei belga de 1903, ao estabelecer uma obrigatoriedade indireta de seguro traduzida na imposição, para os empregadores sem seguro, da constituição dum depósito bancário como garantia de indemnizações e pensões eventualmente por eles devidas.

5 Pouco tempo depois, o Decreto n.. 5637, de 10 de maio de 1919, instituirá "o seguro social obrigatório contra os desastres no trabalho", inserindo, neste modelo que consagra o princípio de seguro obrigatório, as doenças profissionais, tal como eram entendidas na época [1]. Passa a abranger todas as atividades profissionais e o conceito de "desastre no trabalho" apreenderá "toda a lesão interna ou externa e toda perturbação nervosa ou psíquica, que resulte da ação duma violência exterior súbita, produzida durante o exercício profissional ; as intoxicações agudas produzidas durante e por causa do exercício profissional, e as inflamações das bolsas serosas profissionais ; e todos os casos de doenças profissionais devidamente comprovadas“ (art. $3^{\circ}$ ).

6 Contudo, este primeiro sistema de previdência social, assente em seguros sociais obrigatórios, quer para os acidentes de trabalho (AT) e doenças profissionais (DP), quer para a doença, a velhice e a invalidez, nunca chegará a ser realmente implementado, por variadíssimas razões, quase todas elas relacionadas com as turbulências políticas e sociais vividas nos finais da I República (Halpern-Pereira, 1999).

7 Aliás, em 25 de novembro de 1925, o Ministério do Trabalho e Previdência Social, que tinha sido criado em 1916, é extinto e o golpe de estado militar de 28 de maio de 1926 instituirá uma Ditadura Nacional que se prolongará até 1933, transformando-se, então, em Estado Novo [2].

8 Como facilmente se compreende, Portugal viverá durante esse período uma certa indefinição legislativa, um quase vazio normativo, em relação à previdência social, nomeadamente, no que dizia respeito à proteção e reparação dos danos provocados pelos riscos profissionais (Cardoso \& Rocha, 2009). 
Será, então, a Lei n. 1942, de 27 de julho de 1936, já acima referida, que virá clarificar o regime de reparação dos riscos profissionais, no contexto histórico da primeira fase do Estado Novo corporativo de Salazar de 1933. Esta lei, tal como as outras legislações estrangeiras, abrange os AT e as DP ("unidade legislativa dos riscos profissionais"), adotando, contudo, o modelo da obrigatoriedade indireta da transferência para seguradoras da responsabilidade patronal, princípio que tinha já sido consagrado na lei de 1913 da I República.

10 E, em relação às DP estabelece um elenco abreviado de intoxicações e infeções (art. $8^{\circ}$ ), prevendo em anexo um quadro de atividades podendo originar tais doenças, entre as quais o sector mineiro e o fabrico de cimentos, de super-fosfatos, de vidro "e outras indústrias que produzam poeiras contendo carvão, arsénio, sílica, silicatos e tabaco". Anotemos que esta lei retoma, em parte, a nomenclatura das DP consagrada na Convenção OIT n. .92 , modificada em 1934, e que entrou em vigor em 17 de junho de 1936.

11 Portanto, as possíveis indemnizações e pensões resultantes das DP a favor de trabalhadores com vínculo salarial (contrato) eram, em geral, da responsabilidade de seguradoras que na prática se focavam, obviamente, na dimensão estrita da causaefeito ("exercício da profissão causa direta e necessária da doença"), especialmente nos contenciosos judiciários com os assalariados afetados.

\section{A "euforia especulativa", a silicose, "as aldeias das viúvas" e a inquietação do Governo de Salazar}

12 Relembremos, então, que Portugal conhecerá, sobretudo entre o período da GrandeGuerra e os finais dos anos 50 do século passado, um desenvolvimento assinalável da atividade mineira, muito especialmente da extração do volfrâmio (tungsténio), marcada por momentos de grande "euforia especulativa", sobretudo aquando da II Guerramundial. $\mathrm{O}$ mundo do trabalho que se constituiu à volta deste tipo de exploração será fortemente marcado pela sua origem rural e, fora das empresas das grandes e médias concessões, será caracterizado também pelo trabalho informal ou então com vínculos muito precários (Avelãs-Nunes, 2007).

13 Grande parte desta mão-de-obra será assolada pela silicose e, especialmente, a partir dos meados dos anos 50 do século passado, o panorama a nível da saúde pública e a nível social revestirá dimensões calamitosas. Por isso, muitas das aldeias dessas regiões mineiras passarão a ser conhecidas como "as aldeias das viúvas".

14 Numa situação política, sem liberdade sindical (sindicatos oficiais), nem liberdade de imprensa (censura), esta população de trabalhadores esteve completamente abandonada, ou quase, quer em termos de proteção social, quer mesmo a nível da assistência social (por exemplo, a Igreja Católica esteve muito afastada destes problemas). Assim, no fim, após muitos e longos calvários individuais e coletivos, não será a caridade cristã, nem os protestos dos trabalhadores que irão favorecer/ proporcionar a resolução ou a atenuação desses problemas, mas sim a grande inquietação do Governo e de certos quadros da sua Administração perante essa grave questão social. E tudo se passará num contexto político e económico intrincado, em que o regime de Salazar já tinha decidido reformar a sua Previdência Social (Carolo, 2006). 


\subsection{A Reforma da Previdência de 1962}

15 Ainda antes da publicação das bases, sobretudo institucionais, dessa reforma da previdência (Lei n.․ 2115, de 18 de junho de 1962), o Decreto n.. 43189 de 23 de setembro de 1960, adotará finalmente uma Tabela nacional de incapacidades por acidentes de trabalho e doenças profissionais, tendo "como critério básico de avaliação das desvalorizações, o da incapacidade geral de ganho", não deixando, contudo, de explicitar já alguma preocupação em relação à silicose. Por isso, estabelece que os coeficientes a aplicar, na avaliação das incapacidades provocadas por essa doença profissional, terão de ser "especiais, atentas as características peculiares das lesões provocadas (...) e a sua irreversibilidade e as exigências específicas da sua peritagem".

Mas será então o Decreto-lei n.․ 44307, de 27 de abril de 1962 que virá tentar responder “à urgência que a proteção das vítimas da silicose imperiosamente reclama” antes de qualquer revisão do regime geral de reparação dos danos provocados pelos riscos profissionais consagrado na Lei n. 01942 de 1936.

17 Este diploma de 1962, constatando, no seu preâmbulo, a dimensão e gravidade social e médico-sanitária que a silicose naquela época revestia no país, estipula que o seguro daquela doença profissional passará a ser obrigatório e gerido por um organismo público (sem fins lucrativos), integrado no sistema da Previdência Social do Estado Novo. Cria, assim, para esse efeito, a Caixa Nacional de Seguros de Doenças Profissionais (CNSDP), financiada essencialmente por contribuições patronais, e, concomitantemente, aponta que era necessário iniciar um processo no sentido da cobertura dos danos e riscos das doenças profissionais passar gradualmente a ser assumida e gerida pela Previdência Social (responsabilidade social).

Daí que o Governo de Salazar tivesse logo considerado que esta nova "Caixa abrangerá de início, a cobertura do risco da silicose e, se necessário, estender-se-á às demais pneumoconioses e a outras doenças profissionais graves". Definindo, deste modo, a missão futura da C.N.S.D.P. como devendo "assegurar a reparação das doenças profissionais e a recuperação dos trabalhadores que delas sejam vítimas (...)" (artigos $2^{\circ}$ e $3^{\circ}$ do Dec.-lei n. ${ }^{\circ} 44307$ ).

19 Na verdade, o poder político da época foi obrigado a reconhecer publicamente que o panorama nacional, em relação à situação dos trabalhadores afetados pela silicose, era "vivamente desolador". E que os "numerosos processos instaurados nos tribunais do trabalho" evidenciavam "a ineficácia do atual regime de seguro privado" (preâmbulo do Decreto-lei n.. 44307 ).

Tudo isso revelava também que a confrontalidade entre trabalhadores e entidades patronais em matéria de danos causados pelos riscos profissionais, quando se processa no âmbito dum regime/sistema de seguro privado obrigatório, é transferida para um plano de enfrentamento entre seguradoras e trabalhadores sinistrados, cujo epílogo é frequentemente decidido pelo poder judicial (tribunais). Tais mediações tendem a esbater os confrontos entre os interesses intrinsecamente antagónicos em jogo nesses conflitos, que não raras vezes acabam por ser dolorosos, penalizadores e destruturantes para os trabalhadores (Lacomblez \& Leitão, 2018). 


\subsection{A silicose e a os primeiros tempos da medicina do trabalho} de constatar, nesse mesmo preâmbulo, que "a progressiva industrialização do país não tem sido suficientemente acompanhada pelo desenvolvimento de serviços de medicina do trabalho nas empresas", fazendo, em seguida, um inventário do que existia, então, nesse domínio, em Portugal. E notará que, "apesar de tudo", tais serviços já eram obrigatórios, desde 1962/63, "nas indústrias com risco de silicose", além dos previstos em certas convenções coletivas de trabalho e daqueles que certas grandes empresas (como a CUF, a CP, a Siderurgia Nacional e certos estaleiros navais de Lisboa) tinham criado voluntariamente. Era esse o panorama geral, em 1967, dos serviços de medicina do trabalho nas empresas em Portugal. Panorama esse que pouco vai mudar até ao 25 de Abril de 1974. E que continuará nos anos seguintes.

É evidente que preocupações com a gestão do mercado de trabalho da época também estavam presentes nos processos destas reformas, dadas especialmente as mutações que esse mercado vinha conhecendo em Portugal, resultantes, sobretudo, da enorme 
emigração para a Europa ocidental e da vasta mobilização de mão-de-obra masculina jovem para a guerra colonial em África. Além disso, toda esta atividade legislativa visando o progresso da proteção social dos trabalhadores, insere-se na ação políticoideológica do regime político de Salazar que procurará reforçar a sua legitimidade interna no quadro da situação de guerra colonial, mas também tentará retocar, deste modo, alguns dos contornos negativos que muitas vezes eram associados à presença do país na cena internacional.

Relembremos ainda que, no quadro desta reforma da Previdência Social de 1962, o governo de Salazar adotará a Lei n.․ 2127, de 3 de agosto de 1965, que revogará finalmente a Lei n.. 1942, de 27 de julho de 1936, estabelecendo, deste modo, um novo regime jurídico para a reparação dos danos causados pelos AT e pelas DP. No que concerne os AT mantém o regime de seguro privado (tendencialmente obrigatório) e no respeitante às DP mantém também o mesmo regime de seguro privado, exceto "se o risco estiver coberto pela CNSDP" (n. 3 da Base XLIII da Lei), o que acontecia na época só com o risco de silicose.

Assinalemos que, todavia, esta lei só entrará em vigor em finais de 1971, após a sua regulamentação pelo Decreto n. ${ }^{\circ} 360 / 71$, de 21 de agosto, adotado, pois, já durante o período do consulado de Marcelo Caetano (finais de 1968 a 25 de abril de 1974). E será também o Governo de Caetano que publicará a primeira Lista nacional de doenças profissionais (Decreto n.․ 434/73, de 25 de agosto) e determinará, através do Decreto-lei n.. 478/73, de 27 de setembro, que a CNSDP passe a abranger a generalidade das entidades patronais, legislação que só entrou em vigor em 1 de janeiro de 1976, já depois da Revolução do 25 de Abril.

\section{Uma herança que perdurará após 1974}

Será o Decreto-lei n. 200/81, de 9 de julho, que realizará a efetiva e plena integração da proteção do risco de doença profissional no regime geral da agora segurança social. Proteção essa que ficou completamente desligada, a partir de 1 de outubro de 1981, data da entrada em vigor desse decreto-lei, da atividade seguradora privada. Assim, as seguradoras deixaram de poder cobrir, no quadro dos contratos do ramo acidentes de trabalho, as doenças profissionais (Decreto-lei n... 227/81, de 18 de julho).

Todavia, o legislador não operou qualquer dissociação entre este novo sistema de proteção das doenças profissionais com o regime geral de proteção dos riscos profissionais estabelecido na Lei n.․ 2127 de 1965 e no Decreto n.․ 360/71, que ainda continuará em vigor. Só em 1997, a Lei n.․ 100, de 27 de agosto, procederá à revogação da lei de 1965 e da sua regulamentação de 1971, consagrando, enfim, um "novo regime geral" para os acidentes de trabalho e doenças profissionais. Mas tal regime previa uma regulamentação autónoma para a proteção de cada um desses riscos, desde logo, porque os respetivos modelos/sistemas de proteção eram, e continuam a ser ainda hoje, diferentes. Assim, será o Decreto-lei n. 143/99, de 30 de abril, que regulamentará o regime dos acidentes de trabalho, assente nos seguros privados obrigatórios, e, por sua vez, o Decreto-lei n. 248/99, de 2 de julho, regulamentará o respeitante à reparação das doenças profissionais. Daí que o regime jurídico anterior, que vigorava desde finais de 1971, só terminará a sua vigência no dia 1 de janeiro de 2000, isto é, 27 anos e meio após a Revolução democrática. 
, no que diz respeito à reparação dos danos das doenças profissionais, o Decreto-lei n.. 248/99 vai tentar atualizar uma legislação que datava de há mais de 30 anos, adaptando-a à "nova filosofia da proteção social", às "próprias alterações dos factos sociais" e ao regime geral da nova segurança social. Aponte-se, também, que a Caixa Nacional de Seguros de Doenças Profissionais, criada em 1962, como já reportado, será substituída, através da Lei n.․ 160/99, de 11 de maio, pelo Centro Nacional de Proteção contra os Riscos Profissionais (CNPRP), ao qual sucederá, mais tarde, na sequência do estabelecido na Lei n.․ 83/2012, de 8 de maio, o Departamento de proteção contra os riscos profissionais do Instituto da Segurança Social.

À guisa de conclusão, diremos que este "novo regime geral", que, por sua vez, vai vigorar até finais de 2009, retoma, com alguns aperfeiçoamentos relativamente à proteção e aos direitos dos trabalhadores, os traços estruturantes do sistema e do quadro normativo do(s) regime(s) jurídico(s) estabelecido(s) pelos Governos de Salazar e de Caetano (Guibentif, 1997). E, na verdade, tal herança perdura até aos dias de hoje (Gomes, 2013).

\section{BIBLIOGRAFIA}

Amaro, A.R. (2008). O modelo de previdência social do Estado Novo (1933-1962). In L. R. Torgal \& H. Paulo (Coord.), Estados autoritários e totalitários e suas representações (pp. 65-79). Imprensa da Universidade de Coimbra.

Avelãs-Nunes, J.P. (2007). Efeitos colaterais do "fomento industrial". O exemplo do subsector português do volfrâmio até à década de 1950. HISTÓRIA, Revista da Faculdade de Letras, 8, 273-297.

Cardoso, J.L., \& Rocha, M.M. (2009). O seguro social obrigatório (1919-1928) : ação e limites de um Estado previdente. Análise Social, 44(192), 439-470. Retirado de http://www.scielo.mec.pt/ scielo.php?script=sci_arttext\&pid=S0003-25732009000300001\&lng=pt\&tlng=pt.

Carolo, D. (2006). A reforma da Previdência Social de 1962 na institucionalização do Estado-Providência em Portugal. Dissertação de Mestrado, Instituto Superior de Economia e Gestão, Lisboa.

Esping-Andersen, G. (1993). Orçamentos e Democracia : O Estado-Providência em Espanha e Portugal, 1960-1986. Análise Social, 38(122), 589-606.

Gomes, J.M.V. (2013). 0 acidente de trabalho - Acidente in itinere e a sua descaracterização. Coimbra: Coimbra Editora.

Guibentif, P. (1997). The transformation of the Portuguese social security system. In M. Rhodes (Ed.), Southern European Welfare States. Between Crisis and Reform (pp. 219-239). Londres: Routledge.

Halpern-Pereira, M. (1999). As origens do Estado-providência em Portugal : as novas fronteiras entre o público e o privado. In A Primeira República Portuguesa-entre o Liberalismo e o Autoritarismo (pp. 47-76). Lisboa : Edições Colibri.

Laboreal, Volume 15 N² | 2019 
Lacomblez, M., \& Leitão, A.R. (2018). O regresso ao trabalho após um acidente de trabalho : apresentação do dossier. Laboreal, 14(1), 9-12. http://dx.doi.org/10.15667/LABOREALXIV0118ML

\section{NOTAS}

1. Este decreto faz parte de um conjunto de diplomas ("pacote legislativo") que estabeleceram, em maio de 1919, o primeiro sistema integrado de segurança social (ou previdência social) obrigatório. Desse pacote faziam ainda parte: o Decreto n. 5636 que criou o seguro social obrigatório para a doença; o Decreto n. 5638 que estabelecia o seguro social obrigatório contra a invalidez, velhice e sobrevivência; o Decreto n.․ 5639 que previa a (re)organização das bolsas sociais de trabalho; e o Decreto n. 5640 que criava o Instituto de Seguros Sociais Obrigatórios e da Previdência Geral, cuja missão principal era a de implementar este sistema de previdência social.

2. Ficou, pois, a intenção da criação dum primeiro sistema de previdência social obrigatório, por parte dum sector da classe política republicana sensível à proteção social dos trabalhadores e, igualmente, empenhado na institucionalização da OIT (1919) e na "pacificação e harmonia da sociedade futura" através das negociações do Tratado de Paz de Versalhes. Para estes republicanos, radicais e socialistas, "o novo estado social criado pela República" teria "de tornar uma realidade a aliança entre o capital e o trabalho", assente "num espírito de justiça e equidade" (preâmbulo do Decreto n. 5637). Foi, por esta via, que o Estado republicano tentou promover a implementação dum sistema integrado de previdência social, sobretudo através das mutualidades, sendo a sua comparticipação financeira insignificante, dado, desde logo, o contexto económico-financeiro do país no pós-Grande-Guerra (Esping-Andersen, 1993).

\section{AUTOR}

\section{AUGUSTO ROGÉRIO LEITÃO}

Faculdade de Economia, Universidade de Coimbra Av. Dr. Dias da Silva 165 3004-512 Coimbra \& Centro Observare, Universidade Autónoma de Lisboa, Rua Santa Marta 56, 1169-023 Lisboa, Portugal arrcleitao@sapo.pt 